\title{
Environmental Iodine in Iodine Deficiency Disorders with a Sri Lankan Example
}

Fiona M Fordyce ${ }^{1}$, Chris C Johnson ${ }^{2}$, Chandra B Dissanayake ${ }^{3}$ and Udaya R B Navaratne $^{3}$

1. British Geological Survey, West Mains Road, Edinburgh, EH9 3LA, UK

2. British Geological Survey, Keyworth, Nottingham, NG12 5GG, UK

3. Dept. of Geology, University of Peradenyia, Kandy, Sri Lanka

\section{IODINE DEFICIENCY DISORDERS}

Iodine is an essential element for human and other animal health and forms an important constituent of the thyroid hormones thyroxine (T4, also known as tetraiodothyronine) and triiodothyronine (T3). These hormones play a fundamental biological role controlling growth and development (Hetzel and Maberly, 1986). If the amount of utilisable iodine reaching the thyroid gland is inadequate, or if thyroid function is impaired, hormone production can be reduced resulting in a group of conditions collectively referred to as Iodine Deficiency Disorders (IDD) (Fernando et al., 1987; Hetzel, 1989). The World Health Organisation (WHO, 1993) estimate that in excess of one billion people world-wide are at risk from IDD, the most common manifestation of which is goitre (Figure 1). Iodine deficiency is the world's most common cause of preventable mental retardation and brain damage, and has a significant negative impact on the social and economic development of communities.

Although it is likely that IDD are multi-factorial diseases involving other trace element deficiencies and goitrogens (goitre-promoting substances) in foodstuffs, a lack of adequate dietary iodine remains a major concern (Stewart and Pharaoh, 1996). The link between environmental iodine and IDD has been known for the last 80 years. During this time, the medical community has become well organised when tackling the problem, exemplified by the work of the International Council for the Control of IDD (ICCIDD) (http://www.tulane.edu/ icec/icciddhome.htm), which provides an excellent dissemination point for discussion and information. Remediation strategies often focus on enhancing dietary intakes of iodine via the introduction of iodinated salt and iodinated oil programmes (Stanbury and Hetzel, 1980). However, these methods are not always successful and other strategies, including environmental interventions, require development (DeLong et al., 1997). In contrast to the wealth of information about the symptoms, assessment and treatment of IDD, there is very little on the primary cause, a lack of readily available iodine in the environment and diet.

\section{ENVIRONMENTAL IODINE}

Our knowledge of environmental iodine geochemistry is limited, mainly because the analytical methods for assessment are not routine and iodine is not an element that has 
been systematically determined in geochemical surveys. However, in the past two decades, improved analytical methodologies and an interest in iodine from different perspectives have added much to our knowledge. Exploration geochemists have used iodine as a pathfinder element to locate deeply buried mineralisation, increasing an understanding of iodine movement in rocks and soils (Fuge et al., 1986).

Environmental scientists have demonstrated the importance of atmospheric cycling of this element from the oceans (e.g. Alicke et al., 1999). More recently, research into the behaviour of iodine in the environment has been connected to the nuclear industry and the threat posed by radionuclides of iodine. In the aftermath of nuclear accidents, I-131 readily finds its way through the food chain to humans where it is preferentially concentrated in the thyroid and may lead to thyroid cancer (Tuttle and Becker, 2000). Research in this field, has led to a much better understanding of the migration of iodine in the environment. In particular, soil fixation and volatilisation to the atmosphere from the soil-plant interface are both far more significant in the geochemical cycle of iodine than previously recognised (Muramatsu et al., 1995; Schmidtz and Aumann, 1995).

Despite these recent advances, there are myths surrounding environmental iodine that perpetuate in the literature. Glaciated soils are often quoted as low in iodine although there is no real evidence to support this and communities in remote highland regions are commonly cited as being most at risk from IDD (WHO, 1993). Whether this is due to the remoteness or to environmental factors has not been established (Stewart and Pharaoh, 1996).

Whilst it is a well known fact that the oceans constitute major environmental sinks for iodine, which is volatilised from seawater and deposited on land during precipitation, investigators often assume a linear relationship between iodine concentrations and distance from the sea (See Steinnes this volume). However, there is growing evidence to suggest that the mechanisms of iodine volatilisation and transport are complex (Fuge, 1996).

\section{IODINE AND GOITRE IN SRI LANKA}

A case in point is the island of Sri Lanka. Located in the Indian Ocean, no part of the island is more than $110 \mathrm{~km}$ from the sea and yet endemic goitre (estimated to affect 10 million people (Fernando, 1987)) has been recorded for the past 50 years. Goitre prevalence closely follows the climato-topographic regions of Sri Lanka and is a greater problem in the Wet Zone in the centre and southwest of the island than in the Dry Zone to the north (Figure 2). Interestingly, the southwest coastal region has some of the highest prevalences of goitre (Fordyce et al, 1998). Previous investigators had suggested that iodine was washed out of the soil by high rainfall in the Wet Zone hence the high goitre prevalence in this region (Mahadeva \& Shanmuganathan, 1967). Although iodinated salt programmes have been introduced in Sri Lanka, these have been only partially successful due to poor uptake (Dr ABC Amarasinghe, pers. communication).

In a project to investigate the selenium and iodine status of the environment and population of Sri Lanka, the present investigators examined the relationships between 
soil geochemisty and rice, the staple food crop of Sri Lanka. Soil and rice samples (n $=75$ ) were collected from 15 villages, 5 in each of three goitre prevalence areas: low (NIDD) < 10\%; moderate (MIDD) 10-25\% and high (HIDD) $>25 \%$ (Figure 2). Total iodine concentrations were determined in soils by an automated colorimetric method (Fuge et al., 1978) and in 15 composite rice samples (1 composite per village) by epithermal Neutron Activation Analysis at the Environmental Analysis Section, Imperial College Centre for Environmental Technology, Silwood Park, UK.

Results demonstrated that, contrary to popular belief, the concentrations of soil total iodine in the Wet (HIDD and MIDD) and Dry Zones (NIDD) of Sri Lanka are similar (Figure 3) and are no lower than in soils from other parts of the world where goitre is not prevalent (Fordyce et al., 1998). However, further investigations into the soil geochemistry revealed that soils in the HIDD and MIDD goitre villages had higher organic matter, gibbsite and goethite contents and lower $\mathrm{pH}$ than soils in the nongoitre (NIDD) villages. Thus iodine in the Wet Zone (MIDD and HIDD) is adsorbed onto hydrous oxides and organic matter in the soil, inhibiting bioavailability (Fordyce et al., 1998).

In addition to the soil geochemistry, other factors such as methods of plant uptake also influence the migration of elements from the environment through the human food chain. Muramatsu et al. (1995) working in Japan demonstrated that the soil-to-plant transfer factor for iodine in rice is very poor compared to green leafy vegetables and that iodine in soil can be volatilised as organic/methyl iodine as a result of rice cultivation. The atmosphere is an important source of iodine in plants and atmospheric adsorption rather than soil - root uptake may contribute to rice iodine concentrations. As a consequence, concentrations of iodine in rice are often very low compared to the soils and to other crops.

Due to a combination of the soil geochemistry and poor soil-to-plant transfer ratios, total iodine concentrations in Sri Lankan rice samples were very low $(<40 \mathrm{ng} / \mathrm{g}$ in all but two samples). Therefore, despite forming the bulk of food intake, rice does not constitute a significant source of iodine in the Sri Lankan diet (Fordyce et al., 2000). An understanding of the biogeochemical factors controlling iodine uptake into the food chain is essential if effective environmental remediation strategies are to be developed.

\section{THE FUTURE}

These studies emphasise the need for better information about the distribution and behaviour of iodine in the environment. This knowledge would not only increase our understanding of current environmental intervention schemes, such as the iodination of irrigation waters (DeLong et al., 1997), but could lead to the development of agricultural practices that make more efficient use of iodine already present in the environment to provide additional methods in the fight against IDD. Such schemes require collaboration between geoscientists, agricultural and veterinary specialists and health experts. The British Geological Survey (BGS) in partnership with health and agricultural scientists recently commenced a three year project to address some of the environmental controls on IDD and to make resources relating to iodine behaviour in the environment more available to researchers in this field. Information will be 
disseminated from the project web-site at http://www.bgs.ac.uk/dfid-kar-geoscience/idd. This web-site links to, and will complement more medically oriented information sources such as the ICCIDD.

\section{REFERENCES}

Alicke, B., Hebestreit, K., Stutz, J. and Platt, U. (1999) Iodine oxide in the marine boundary layer. Nature, 397, 6720, 572-573.

DeLong, G.R., Leslie, P. W., Wang, S. H., Jiang, X. M., Zhang, M. L., Rakeman, M. A., Jiang, J. Y., Ma, T. and Cao, X. Y. (1997). Effect on infant mortality of iodination of irrigation water in a severely iodine-deficient area of China. Lancet, 350, 9080, 771-773.

Fernando, M.A., Balasuriya S., Herath K.B., Katugampola, S. (1987). Endemic goitre in Sri Lanka. In: Dissanayake, C.B., Gunatilaka, L., editors. Some Aspects of the Environment of Sri Lanka. Sri Lanka. Association for the Advancement of Science, Colombo. 46-64.

Fordyce, F.M., Johnson, C.C., Navaratne, U.R.B., Appleton, J.D. and Dissanayake, C.B. (1998). Studies of Selenium Geochemistry and Distribution in Relation to Iodine Deficiency Disorders in Sri Lanka. British Geological Survey Overseas Geology Series Technical Report WC/98/23.

Fordyce, F.M., Johnson, C.C., Navaratne, U.R B., Appleton, J.D. and Dissanayake C.B. (2000). Selenium and iodine in soil, rice and drinking water in relation to endemic goitre in Sri Lanka. The Science of the Total Environment. 263, 1-3, 127142.

Fuge R. (1996). Geochemistry of iodine in relation to iodine deficiency diseases. In: Appleton, J.D., Fuge R., McCall, G.J.H., editors. Environmental Geochemistry and Health, Geological Society Special Publication. 113, 201-212.

Fuge, R., Andrews, M.J. and Johnson, C.C. (1986). Chlorine and iodine, potential pathfinder elements in exploration geochemistry. Applied Geochemistry 1, 111-116.

Fuge, R., Johnson, C.C., Phillips, W.J. (1978). An automated method for the determination of iodine in geochemical samples. Chemical Geology 23, 255-265.

Hetzel B. S. (1989) The Story of Iodine Deficiency. Oxford University Press, Oxford.

Hetzel, B.S. and Maberly, G.F. (1986). Iodine. In: Mertz, W., editor. Trace Elements in Human and Animal Nutrition. Academic Press, London. 139-197.

Mahadeva, K., Senthe Shanmuganathan, S. (1967). The problem of goitre in Ceylon. British Journal of Nutrition 21, 341-352. 
Muramatsu, Y, Yoshida, S and Ban-nai, T. (1995). Tracer experiments on the behaviour of radioiodine in the soil-plant-atmosphere system. Journal of

Radioanalytical and Nuclear Chemistry. 194, 2, 303-310.

Schmitz, K, and Aumann, D.C. (1995). A study on the association of two iodine isotopes, of natural I-127 and of the fission product I-129, with soil components using a sequential extraction procedure. Journal of Radioanalytical and Nuclear Chemistry, Articles, 198, 1, 229-236.

Stanbury, J. and Hetzel, B. S. (1980). Endemic Goiter and Endemic Cretinism Iodine Nutrition in Health and Disease. Wiley, Chichester.

Tuttle, R.M. and Becker, D.V. (2000). The Chernobyl accident and its consequences: update at the millennium. Seminars in Nuclear Medicine. 30, 2, 133-140

Stewart, A.G. and Pharoah, P.O.D. (1996). Clinical and epidemiological correlates of iodine deficiency disorders. In: Appleton, J.D., Fuge R., McCall, G.J.H., editors. Environmental Geochemistry and Health, Geological Society Special Publication. 113, 201-212.

World Health Organisation (1993). Micronutrient Deficiency Information System: Global Prevalence of Iodine Deficiency Disorders. WHO/UNICEF/ICCIDD, Geneva

World Health Organisation. (1996) Trace Elements in Human Nutrition and Health. World Health Organisation, Geneva.

\section{ACKNOWLEDEGEMENTS}

The work presented in this paper is sponsored by the UK Department for International Development (DFID) projects R6227 and R7411.

The authors gratefully acknowledge the assistance of Dr R Fuge (University College of Wales, Aberystwyth, UK), Dr R Benzing (Environmental Analysis Section, Imperial College Centre for Environmental Technology, Silwood Park, UK) and Dr Mark Cave (BGS) for analysis; Dr Neil Breward (BGS) and Dr Alex Stewart (Wirral Health Authority, UK) for comments on the text and Dr ABC Amarasinghe, Dept of Biochemistry, University of Peradeniya, Sri Lanka for advice on the prevalence of IDD in Sri Lanka.

Published with permission from the Director of the British Geological Survey (NERC). 


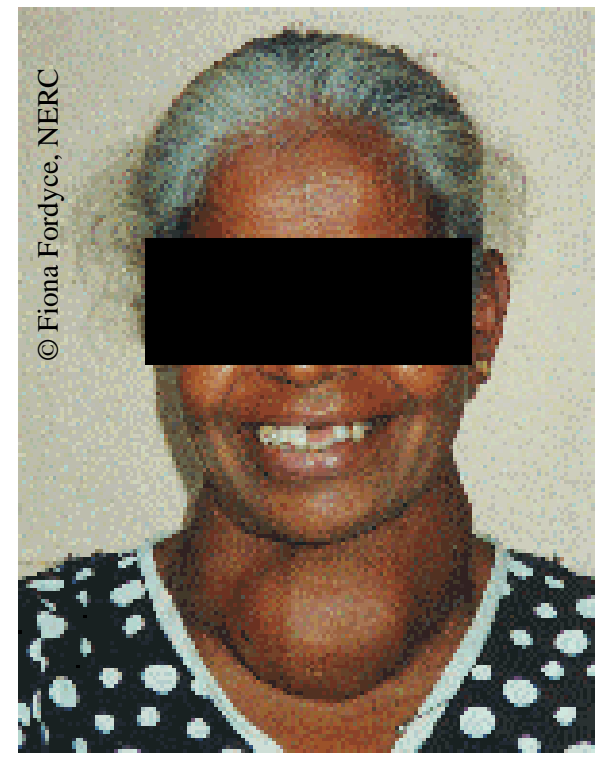

Fig. 1. Sri Lankan woman suffering from the iodine deficiency disorder goitre. 


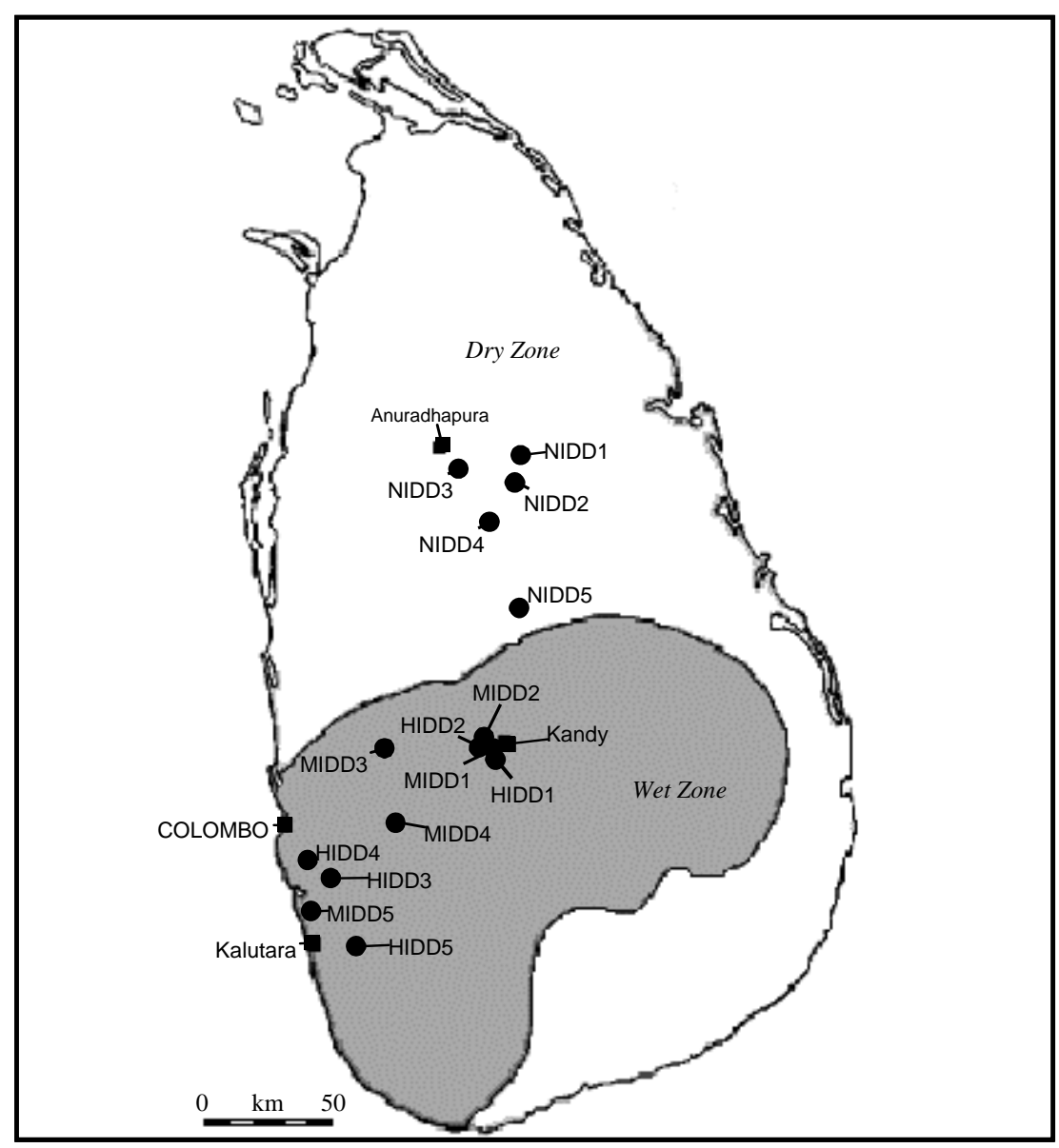

Fig. 2. Sketch map showing the location of the 15 study villages, the Wet Zone/ Dry Zone demarcation used in the present study is based on the 2000-mm isohyet. The three groups of goitre prevalence villages are as follows: NIDD $=$ No/low $<10 \%$ goitre prevalence; MIDD = Moderate 10 - 25\% goitre prevalence and HIDD $=$ High $>$ $25 \%$ goitre prevalence. 


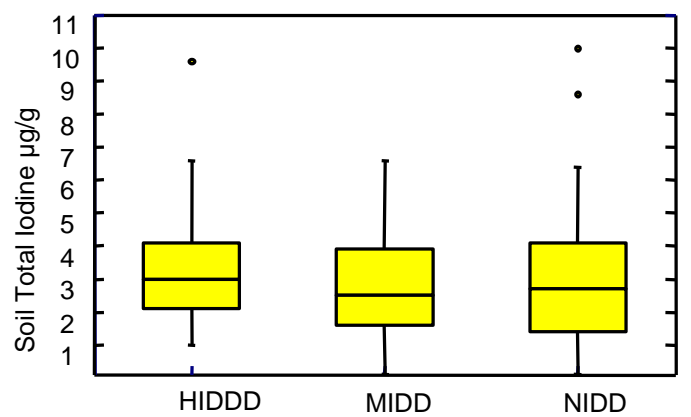

Fig. 3. Box and whisker plots of the $10^{\text {th }}, 25^{\text {th }}, 50^{\text {th }}, 75^{\text {th }}$, and $90^{\text {th }}$ percentiles of soil total iodine concentrations classified by goitre prevalence. NIDD $=$ No/low $<10 \%$ goitre prevalence; MIDD = Moderate $10-25 \%$ goitre prevalence and HIDD $=$ High $>$ $25 \%$ goitre prevalence. 